\title{
Multiaxial high-cycle fatigue modelling for random loading
}

\author{
Haoyang Wei ${ }^{1}$, Jie Chen ${ }^{1}$, Patricio Carrion ${ }^{2,3}$, Anahita Imanian ${ }^{4}$, Nima Shamsaei ${ }^{2,3}$, \\ Nagaraja Iyyer ${ }^{4}$ and Yongming Liu ${ }^{1,1}$ \\ ${ }^{1}$ Department of Mechanical Engineering, Arizona State University, Tempe, AZ 85287, USA \\ ${ }^{2}$ National Center for Additive Manufacturing Excellence (NCAME), Auburn University, Auburn, AL \\ 36849, USA \\ ${ }^{3}$ Department of Mechanical Engineering, Auburn University, Auburn, AL 36849, USA \\ ${ }^{4}$ Technical Data Analysis, Inc., Falls Church, VA 22042, USA
}

\begin{abstract}
In this paper, a multiaxial fatigue life prediction model is proposed under general multiaxial random loadings. First, a brief review for existing multiaxial fatigue models is given and special focus is on the LiuMahadevan critical plane concept, which can be applied to both brittle and ductile materials. Next, new model development based on the LiuMahadevan critical plane concept for random loading is presented. The key concept is to use two-steps to identify the critical plane: identify the maximum damage plane due to normal stress and calculate the critical plane orientation with respect to the maximum damage plane due to normal stress. Multiaxial rain-flow cycle counting method with mean stress correction is used to estimate the damage on the critical plane. Equivalent stress transformation is proposed to convert the multiaxial random load spectrum to an equivalent constant amplitude spectrum. The equivalent stress is used for fatigue life prediction. Following this, experimental design and testing is performed for Al 7075-T6 under various different random uniaxial and multiaxial spectrums. The developed model is validated with both literature and in-house testing data. Very good agreement is observed for the investigated material. Finally, conclusion and future work is given based on the proposed study.
\end{abstract}

\section{Introduction}

Multiaxial fatigue models can be classified into four major categories: stress-based [1-3], strain-based [4,5], energy-based [6,7], and fracture mechanics-based approaches [8]. Employed under any of these categories, there is a criterion that offers a physical interpretation of the fatigue damage by relating the crack orientation (initiation and propagation) to a plane of critical loading, known as the "critical plane approach".

The basic concept of the critical plane approach is to use the stress/strain components on a plane to calculate the fatigue damage of material under general multiaxial cyclic loadings. Many models assume the maximum shear stress plane as the critical plane, which is suitable

\footnotetext{
Corresponding author: yongming.liu@asu.edu
} 
for ductile failure $[9,10]$. Other models assume that the maximum normal stress range plane as the critical plane which is mostly suitable for brittle failure [11-13]. However, when these two failure modes mix, or the material is neither ductile nor brittle, it is difficult to select an appropriate model. Furthermore, the fatigue life regime (i.e. low-cycle or high-cycle) can also change a materials failure mode [14]. Several attempts trying to solve this issue have been proposed in the past $[18,19]$. One successful approach is to let the critical plane change its orientation for different failure modes, i.e., along the maximum normal stress range plane for brittle materials and along the maximum shear stress range plane for ductile materials. The concept was initially proposed using an empirical function [15-17].

Liu and Mahadevan [18,19] proposed an analytical solution for the critical plane orientation based on the material ductility. The concept was first applied using the stressbased approach for high-cycle fatigue [18] and was later extended for low-cycle fatigue using a strain-based model [19]. Extensive model validations for this concept have been performed for both brittle and ductile materials at the material and component level. However, since only the strain terms are used in the model [19], it cannot include the out-of-phase hardening behaviour explicitly. Out-of-phase loading causes rotation of the direction of the principal stresses. The rotation brings additional hardening to the material due to the activation of many more slip planes, which causes an increase in stress response and thus reduces the fatigue life. In order to compensate for the out-of-phase hardening, empirical calibration parameters are used $[19,20]$, which are adjusted using a few out-of-phase multiaxial fatigue tests. Wei and Liu [21] proposed an energy-based model integrating the Liu-Mahadevan critical plane concept. The energy-based model can be applied to a wide range of materials (both brittle and ductile) under both proportional and non-proportional loadings without the need of calibration parameters.

In this paper, the Liu-Mahadevan critical plane concept, is extended for random fatigue loading. Many existing fatigue criteria for random loading are in time domain [22] and frequency domain [23]. Usually time domain approaches are based on a cycle counting method and a cumulative damage rule. Rainflow counting method as a cycle counting method is widely used for random loading fatigue analysis. Carpinteri et al. [24] proposed a new cycle counting procedure for normal stress on critical plane. Among all the fatigue damage accumulation rules, the LDR (linear damage accumulation rule), also known as Miner's rule, is probably the most commonly used due to simplicity.

Based on the above discussion, the authors attempt to develop a multiaxial fatigue model for random loading by integrating the Liu-Mahadevan critical plane approach along with Rainflow counting and Miner's damage rule, from which an equivalent stress on critical plane can be calculated and used to determine fatigue life with the proposed model.

\section{Multiaxial stress-based model for HCF}

\subsection{Stress-based model}

Liu and Mahadevan proposed a stress-based fatigue life prediction model for constant multiaxial loading condition [18]. This stress-based model is given in Eq. (1),

$$
\sqrt{\left(\frac{\sigma_{a, c}}{f_{-1}}\right)^{2}+\left(\frac{\tau_{a, c}}{t_{-1}}\right)^{2}+k\left(\frac{\sigma_{a, c}^{H}}{f_{-1}}\right)^{2}}=\beta
$$

where $\sigma_{a, c}, \tau_{a, c}, \sigma_{a, c}^{H}$ are the normal, shear, and hydrostatic stress amplitudes acting on the critical plane, respectively. $f_{-1}$ and $t_{-1}$ are uniaxial and torsional fatigue stress limits for fully-reversed constant amplitude loading, respectively. Parameters $\mathrm{k}$ and $\beta$ are material 
constants determined from uniaxial and pure torsional fully-reversed tests. Eq. (1) represents the summation of the damage caused by normal, shear and hydrostatic stress components

This stress-based constant multiaxial loading fatigue model is extended to multiaxial variable loading by following the same logic, the critical plane under a given multiaxial variable amplitude load path is determined first, then the summation of equivalent damage from normal, shear and hydrostatic stresses on the critical plane is calculated. This is shown in Eq. (2),

$$
\sqrt{\left(\frac{\sigma_{a, c}^{e q}}{f_{-1}}\right)^{2}+\left(\frac{\tau_{a, c}^{e q}}{t_{-1}}\right)^{2}+k\left(\frac{\sigma_{a, c}^{e q, H}}{f_{-1}}\right)^{2}}=\beta
$$

where $\sigma_{a, c}^{e q} \tau_{a, c}^{e q}$ and $\sigma_{a, c}^{e q, H}$ are the equivalent normal, shear, and hydrostatic stress amplitudes acting on the critical plane, respectively. A detailed procedure for computing the equivalent stress on the critical plane is shown in the following section.

\subsection{Critical plane}

For the proposed model, it is assumed that under variable loading condition, the fatigue fracture plane is the maximum damage plane, and damage occurs due to the normal stress amplitude acting on that plane. Normal stress spectrum on all possible orientations is computed and then the plane with maximum damage due to normal stress amplitude is found using the rainflow counting algorithm and Miner's rule. This plane is also called fatigue fracture plane as the final fracture of specimen is usually along this plan since mode I crack is usually the final fracture mode. The critical plane is different from the fatigue fracture plane, and the angle $\alpha$ between them is determined by the material ductility. It is computed using experiment result for tensile and torsional test. For ductile materials, $\alpha=45^{\circ}$, $\mathrm{k}=9\left[\left(t_{-1} / f_{-1}\right)^{2}-1\right]$ and $\beta=t_{-1} / f_{-1}$. For brittle materials, $\alpha$ is $0^{\circ}, \mathrm{k}=\frac{9}{4}\left[3-\left(t_{-1} / f_{-1}\right)^{2}\right]$ and $\beta=1$. For arbitrary material, the contribution from hydrostatic stress is minimized to be zero and the formula of $\alpha$ and $\beta$ is shown in Eq. (3), and Eq. (4), respectively,

$$
\begin{gathered}
\cos (2 \alpha)=\frac{-2+\sqrt{4-4 \times\left(1 / s^{2}-3\right) \times\left(5-1 / s^{2}-4 s^{2}\right)}}{2 \times\left(5-1 / s^{2}-4 s^{2}\right)} \\
\beta=\sqrt{\cos ^{2}(2 \alpha) s^{2}+\sin ^{2}(2 \alpha)}
\end{gathered}
$$

where $\mathrm{s}=t_{-1} / f_{-1}$.

The critical plane orientation is determined before the normal and shear stress spectrum on critical plane can be obtained.

\subsection{Mean stress correction factor}

The mean stress is introduced into the fatigue model by a correction factor $\left(1+\eta \frac{\sigma_{m}}{\sigma_{y}}\right) \cdot \eta$ is material coefficient, which can be obtained from uniaxial fatigue test with the same mean stress ratio, and $\sigma_{y}$ is the yield stress. It should be noticed that $\sigma_{m}$ acts on the maximum damage plane. Thus, the damage of normal and shear stress on the critical plane is computed using Miner's rule based on the rainflow accounting algorithm, given in Eq. (5) as: 


$$
\left\{\begin{array}{l}
D_{c}^{\sigma}=\sum_{i=1}^{N_{\sigma}} \frac{1}{f\left[\left(1+\eta \frac{\sigma_{m}{ }^{i}}{\sigma_{y}}\right) \sigma_{a, c}^{i}\right]} \\
D_{c}^{\tau}=\sum_{i=1}^{N_{\tau}} \frac{1}{f\left[\left(1+\eta \frac{\sigma_{m}{ }^{i}}{\sigma_{y}}\right) \tau_{a, c}^{i}\right]}
\end{array}\right.
$$

where $N_{\sigma}$ and $N_{\tau}$ are number of cycles of normal and shear stress spectrum on critical plane, $\sigma_{m}{ }^{i}$ is mean stress of $\mathrm{i}^{\text {th }}$ cycle, $\sigma_{a, c}^{i}$ and $\tau_{a, c}^{i}$ are $\mathrm{i}^{\text {th }}$ cycle normal and shear stress amplitude on critical plane, respectively. $f(\sigma)$ is the fatigue life function of the normal or shear stress on the critical plane. Thus, $\frac{1}{f(\sigma)}$ is the fatigue damage under one cycle of normal or shear loading. For example, $f(\sigma)$ could be a power fatigue life function given by Eq. (6).

$$
f(\sigma)=\mathrm{A} \times \sigma^{B}
$$

It should be noticed that the fatigue life function is fitted by pure tensile and pure torsional S-N curves.

\subsection{Equivalent stress components on critical plane}

For stationary variable amplitude loading, damage from normal stress amplitude $D_{c}^{\sigma}$, shear stress amplitude $D_{c}^{\tau}$, and hydrostatic stress amplitude $D_{c}^{H}$ on critical plane for one block is investigated using rainflow accounting algorithm and Miner's rule. Mean stress correction factor is also included. Then equivalent normal stress $\sigma_{a, c}^{e q}$ and shear stress $\tau_{a, c}^{e q}$ on critical plane can be calculated using damage mechanics concept given in Eq. (7),

$$
\left\{\begin{array}{l}
D_{c}^{\sigma}=n \times \frac{1}{f\left(\sigma_{a, c}^{e q}\right)} \\
D_{c}^{\tau}=n \times \frac{1}{f\left(\tau_{a, c}^{e q}\right)}
\end{array}\right.
$$

where $n$ is the applied number of cycles. For consistency, $n$ is assumed to be the total number of cycles or reversals of tensile spectrum from the rainflow accounting algorithm. Combining Eq. (5) and Eq. (7), there are two equations and two unknowns $\sigma_{a, c}^{e q}$ and $\tau_{a, c}^{e q}$ which can be solved.

The random loading block is converted to a proportional loading condition of equivalent normal and shear stress, $\sigma_{a, c}^{e q}, \tau_{a, c}^{e q}$, on critical plane with $n$ number of cycles. The equivalent hydrostatic stress $\sigma_{a, c}^{e q, H}$ can be computed from the average of the hydrostatic stress spectrum since it is not dependent of the critical plane orientation.

\subsection{Fatigue life prediction}


For stationary variable amplitude loading, damage for one block is investigated. Eq. (2) can be rewritten and results in Eq. (8), given as:

$$
\frac{1}{\beta} \sqrt{\left(\frac{\sigma_{a, c}^{e q}}{f_{-1}}\right)^{2}+\left(\frac{\tau_{a, c}^{e q}}{t_{-1}}\right)^{2}+k\left(\frac{\sigma_{a, c}^{e q, H}}{f_{-1}}\right)^{2}}=f_{-1}
$$

The right-hand side of Eq. (5) could be treated as a function of fatigue life based on the uniaxial S-N curve. So, the fatigue model for variable loading condition is expressed in Eq. (9) as:

$$
\frac{1}{\beta} \sqrt{\left(\frac{\sigma_{a, c}^{e q}}{f_{-1}}\right)^{2}+\left(\frac{\tau_{a, c}^{e q}}{t_{-1}}\right)^{2}+k\left(\frac{\sigma_{a, c}^{e q, H}}{f_{-1}}\right)^{2}}=f_{\mathrm{N}}
$$

where $\mathrm{N}$ means the number of blocks or number of reversals.

\section{Experimental testing}

\subsection{Experimental setup}

Fatigue testing was conducted at the National Center for Additive Manufacturing Excellence (NCAME) at Auburn University. The test system used was an MTS 809 close-loop servohydraulic axial-torsion load frame with a load capability of $100 \mathrm{kN}$ and $1100 \mathrm{~N} \mathrm{~m}$. Axial/Torsion tests were conducted at a frequency of $5 \mathrm{~Hz}$, using different sinusoidal load spectrums in force and torque control. The experimental setup and test system are presented in Fig. 1. The load spectrum was repeated until failure, which was defined as either a $5 \%$ increase in the maximum displacement or angle amplitude; or the appearance of a visible crack length of 2 5 $\mathrm{mm}$ on surface. Duplicate tests for proportional loading condition were performed to verify the results obtained.

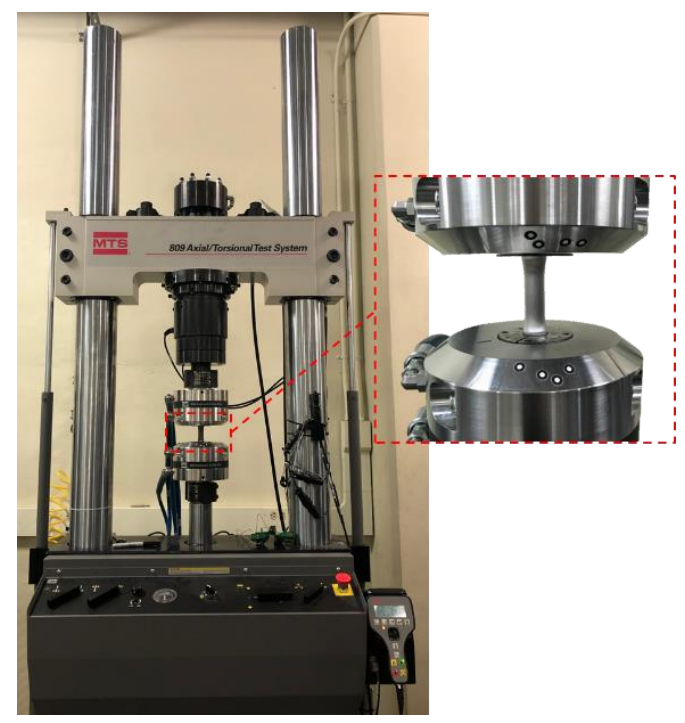

Fig. 1. Experimental testing setup.

\subsection{Experimental design results}

The specimen design follows ASTM standard E2207-15 (shown in Fig. 2). A tubular thinwalled specimen geometry is used to minimize the stress gradient effect across the thickness 
direction. The multiaxial variable amplitude load spectrums used in this study were designed by TDA. The load spectrums included proportional, and non-proportional loadings.

Fatigue test results of Al $7075 \mathrm{~T} 6$ are presented in Table 1, which include the test number, the load spectrum used, and number of reversals to failure.

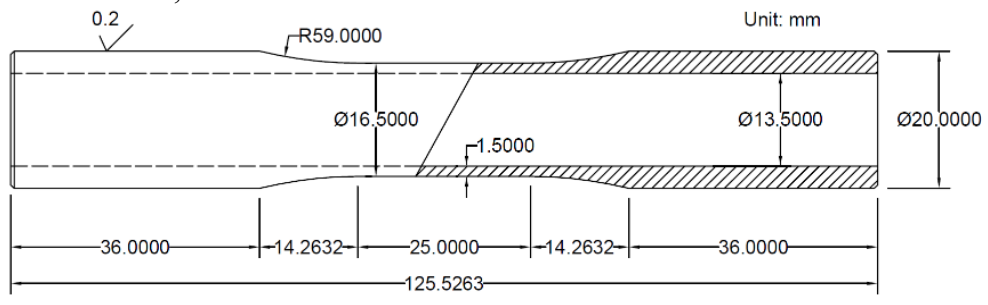

Fig. 2. Specimen design for multiaxial fatigue testing

Table 1. Experimental testing summary.

\begin{tabular}{|c|c|c|c|c|c|}
\hline $\begin{array}{c}\text { Test } \\
\text { No. }\end{array}$ & Load & $\begin{array}{c}\text { Number of } \\
\text { reversals }\end{array}$ & $\begin{array}{c}\text { Test } \\
\text { No. }\end{array}$ & Load & $\begin{array}{c}\text { Number of } \\
\text { reversals }\end{array}$ \\
\hline 1 & $\begin{array}{c}\text { Multiaxial } \\
\text { (Proportional) }\end{array}$ & $1,340,500$ & 7 & Uniaxial & $5,956,555$ \\
\hline 2 & $\begin{array}{c}\text { Multiaxial } \\
\text { (Proportional) }\end{array}$ & $1,748,119$ & 8 & Uniaxial & $1,971,920$ \\
\hline 3 & $\begin{array}{c}\text { Multiaxial } \\
\text { (Non-proportional) }\end{array}$ & $1,221,030$ & 9 & Uniaxial & $2,905,820$ \\
\hline 4 & $\begin{array}{c}\text { Multiaxial } \\
\text { (Proportional) }\end{array}$ & $2,553,210$ & 10 & Uniaxial & $1,196,807$ \\
\hline 5 & $\begin{array}{c}\text { Multiaxial } \\
\text { (Non-proportional) }\end{array}$ & 405,053 & 11 & Uniaxial & $2,112,921$ \\
\hline 6 & Uniaxial & 736,909 & & & \\
\hline
\end{tabular}

\section{Validation and conclusion}

The proposed variable amplitude fatigue model is applied to predict the fatigue life of Al 7075 T6 under uniaxial and multiaxial variable amplitude loading conditions. The material properties and constant loading conditions are from open literature [25]. Young's modulus is $71 \mathrm{GPa}$. Poisson's ratio is 0.3 . Yield stress is $503 \mathrm{MPa}$. The proposed fatigue model predicted fatigue live under multiaxial constant loading condition based on literature [25] and random loading based on our fatigue testing. In order to validate the variable fatigue model, the predicted fatigue lives are compared with the experimentally obtained fatigue lives. The comparison is shown in Fig. 3.

The solid line indicates that the predicted results are identical with experimental results. The dashed lines are the bounds of fatigue life scatter with a factor of \pm 2 . Circle marks indicate constant loading without mean stress. Square marks are uniaxial loading conditions with mean stress. And triangle marks are random loading case results. It can be obtained that the predicted results have a good agreement with experimental results not only under constant loading but also under random loading with or without mean stress, which validates the 
proposed variable loading fatigue model. It is shown that a general good agreement is observed between model prediction and experimental results.

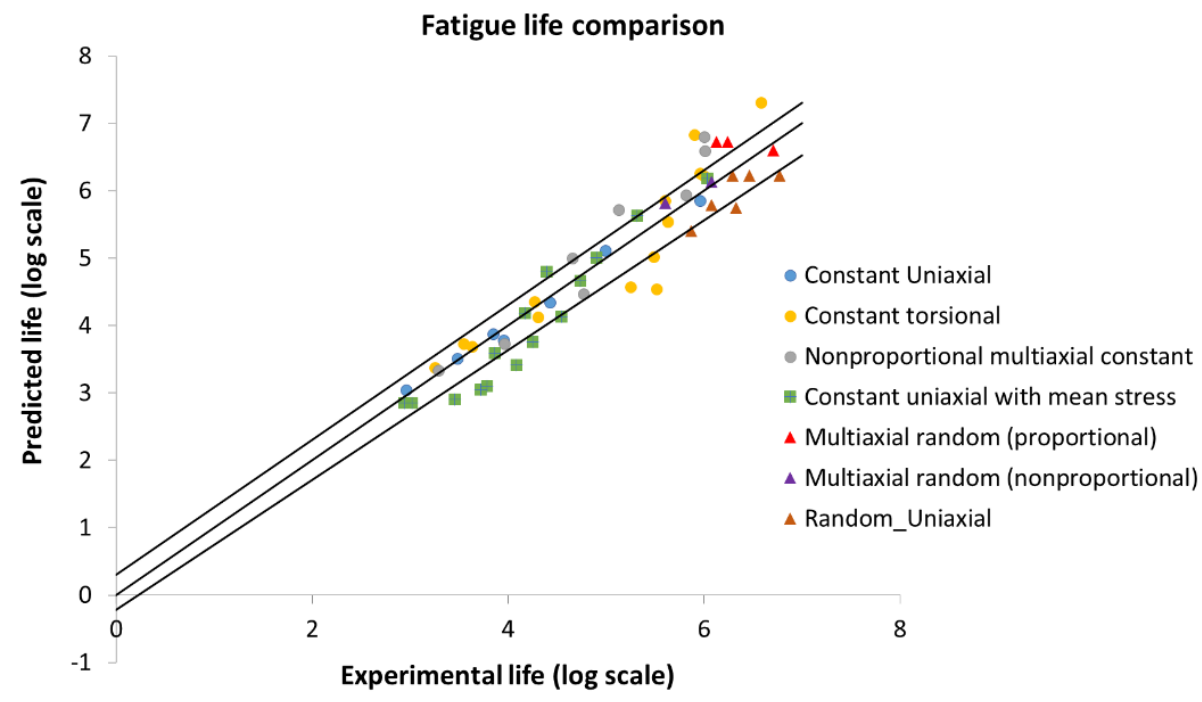

Fig. 3. Comparison of model prediction with experimental results

\section{References}

1. R. E. Little, Fatigue Stresses from Complex Loadings. Mach. Des. 38, 145-149. (1966)

2. B. F. Langer, Design of Pressure Vessels Involving Fatigue. In: Pressure Vessel Engineering Technology, R.W.Nichols, Ed., Elsevier Publishing Co. Ltd., AmsterdamLondon-New York, pp. 59 - 100. (1971)

3. G. Li, S. Datta, A. Chattopadhyay, N. Iyyer, N. Phan, An online-offline prognosis model for fatigue life prediction under biaxial cyclic loading with overloads. Fatigue Fract. Eng. Mater. Struct. (2019)

4. G. Z. Libertiny, Short Life Fatigue under Combined Stresses. J. Strain. Anal. 2, 91-95. (1967)

5. S. Y. Zamrik, An Investigation of Strain Cycling Behavior of 7075-T6 Aluminum under Combined State of Strain. doi:NASA CR-72843 (1972)

6. W. N. Findley, P. N. Mathur, E. Szezepanski, A. O. Temel Energy- versus Stress Theories for Combined Stress--A Fatigue Experiment using a Rotating Disk. J. Basic Eng. A.S.M.E, 83, 10-14. (1961)

7. B. N. Leis, An Energy-Based Fatigue and Creep-Fatigue Damage Parameter. J. Press. Vessel Technol. A.S.M.E. 99, 524-533. (1977)

8. S. Kruch, P. Prigent, J. L. Chaboche, A fracture mechanics based fatigue-creepenvironment crack growth model for high temperature. Int. J. Press. Vessel. 59, 141148. (1994)

9. D. Socie, Multiaxial Fatigue Damage Models. J. Eng. Mater. Technol. 109, 293-298. (1987) 
10. G. Glinka, G. Shen, A. Plumtree, Multiaxial Fatigue Strain Energy Density Parameter Related to the Critical Fracture Plane. Fatigue Fract. Eng. Mater. Struct. 18, 37-46. (1995)

11. K. N. Smith, P. Watson, T. Topper, Stress-Strain Function for the Fatigue of Metals. J. Mater. 5, 767-778. (1970)

12. C. C. Chu, F. A. Conle, J. J. Bonnen, Multiaxial Stress-Strain Modelling and Fatigue Life Prediction of SAE Axle Shafts. Adv. Multiaxial Fatigue. \{ASTM $\{$ STP $119137-$ 54. (1993)

13. K. S. Kim, K. M. Nam, G. J. Kwak, S. M. Hwang, A fatigue life model for $5 \%$ chrome work roll steel under multiaxial loading. Int. J. Fatigue. 26, 683-689. (2004)

14. A. Carpinteri, A. Spagnoli, Multiaxial high-cycle fatigue criterion for hard metals. Int. J. Fatigue. 23, 135-145. (2001)

15. A. Fatemi, N. Shamsaei, Multiaxial fatigue: An overview and some approximation models for life estimation. Int. J. Fatigue. 33(8), pp.948-958. (2011)

16. J.A. Araújo, A. Carpinteri, C. Ronchei, A. Spagnoli, S. Vantadori, An alternative definition of the shear stress amplitude based on the Maximum Rectangular Hull method and application to the C-S (Carpinteri-Spagnoli) criterion. Fatigue Fract. Eng. Mater. Struct. 37(7), pp.764-771. (2014)

17. A. Carpinteri, C. Ronchei, A. Spagnoli, S. Vantadori, Lifetime estimation in the low / medium-cycle regime using the Carpinteri - Spagnoli multiaxial fatigue criterion. Theor. Appl. Fract. Mech. 73, 120-127. (2014)

18. Y. Liu, S. Mahadevan, Multiaxial high-cycle fatigue criterion and life prediction for metals. Int. J. Fatigue. 27, 790-800. (2005)

19. Y. Liu, S. Mahadevan, Strain-based multiaxial fatigue damage modelling. Fatigue Fract. Eng. Mater. Struct. 28, 1177-1189. (2005)

20. M. V. Borodii, V. A. Strizhalo, Analysis of the experimental data on a low cycle fatigue under nonproportional straining. Int. J. Fatigue. 22, 275-282. (2000)

21. H. Wei, Y. Liu, A critical plane-energy model for multiaxial fatigue life prediction. Fatigue Fract. Eng. Mater. Struct. 40(12), pp.1973-1983. (2017)

22. T. Łagoda, E. Macha, A. Niesłony, Fatigue life calculation by means of the cycle counting and spectral methods under multiaxial random loading. Fatigue Fract. Eng. Mater. Struct. 28, 409-420. (2005)

23. X. Pitoiset, I. Rychlik, A. Preumont, Spectral methods to estimate local multiaxial fatigue failure for structures undergoing random vibrations. Fatigue Fract. Eng. Mater. Struct. 24, 715-727. (2001)

24. A. Carpinteri, A. Spagnoli, S. Vantadori, A multiaxial fatigue criterion for random loading. Fatigue Fract. Eng. Mater. Struct. 26(6), pp.515-522. (2003)

25. T. Zhao, Y. Jiang, Fatigue of 7075-T651 aluminum alloy. Int. J. Fatigue. 30(5), pp.834849. (2008) 